\title{
A memória, o esquecimento e o compromisso do historiador ${ }^{*}$
}

Ramon Barroncas ${ }^{1}$

\section{Resumo:}

O artigo parte da discussão sobre o que é a memória, quais usos nós fazemos da memória e do passado e se tais usos podem se tornar abusivos. Qual o compromisso que o historiador deve adotar para utilizar a memória como fonte? Trabalhar com o passado demanda certa responsabilidade - ética e social - dos que se propõe a esse ofício. Entre a amnese e a anamnese, as identidades individuais e coletivas são formadas. Nesse sentido, as memórias definem padrões identitários de uma sociedade. Existe alguma diferença de conduta ética entre os que trabalham com memórias do tempo presente e os que trabalham com memória de um tempo remoto? O artigo discute essas questões levantando questionamentos que surgiram com acontecimentos como os regimes de exceção que ocorreram ao redor do mundo no séc. XX. No caso brasileiro, tais questões reaparecem no contexto de instauração da Comissão Nacional da Verdade, que se propõe a analisar os crimes perpetrados pelo Estado brasileiro durante o período que vai de 1946 até 1988.

Palavras-chave:Memória; História;Direitos Humanos.

\begin{abstract}
:
This article starts with the discussion about what memory is, what uses we make of memory and the past and if these memories can be abusively appropriated by others. What are the ethics a historian must adopt to use memories as sources? A certain social and ethical responsibility is demanded of those who decide to work with the past. In between amnesis and anamnesis, individual and collective identities are formed. In this sense, a memory that is used in an abusive manner can define some of the patterns of identity of a society. Lastly, is there an ethical difference between those who work with present time and those who work with more remote times? The article discusses these issues making a parallel between the authoritarian regimes that sprung up around the world in the 20th Century and the Brazilian National Commission for Truth (Comissão Nacional da Verdade), which aims to analyze crimes committed by the Brazilian government during the period from 1946 to 1988.
\end{abstract}

Key-words: Memory; History; Human Rights.

Não há alma que possa viver sem saudades. Lembrar é viver e reviver. A certeza do hoje nasce da lembrança do ontem: um homem sem recordações seria uma pedra inerte...

Olavo Bilac, A Defesa Nacional.

\footnotetext{
*Artigo submetido em 15.05.2012, e aprovado para publicação em 02.07.2012.

${ }^{1}$ Mestrando em História Cultural pelo Programa de Pós-Graduação em História da Universidade de Brasília. 
A presença de um tempo que já passou é uma constante em nossas vidas. Nascemos num mundo recheado de informações, reminiscências, rastros de um pretérito que não necessariamente foi vivenciado no presente, mas que influencia as relações que estabelecemos com o presente e com o futuro. Alguns desses vestígios permanecem e outros se apagam. Existe certa contingência do que permanece ou não, do que permanece por escolha ou por acaso, do que é enterrado e do que é exumado. Essa cota do que fica e do que se perde é complicada de se mensurar: cada cultura, cada indivíduo, cada sociedade cria relações diversificadas de apropriação e uso desse passado, de acordo com associações de diferentes fatores. Associações que nem sempre são conscientes, voluntárias ou fruto de um grande debate.

Esses registros que permanecem em maior ou menor número representam para o historiador uma ferramenta importante para o seu ofício. São esses indícios que o historiador transforma em fonte para seus estudos: uma base que o auxilia na produção do conhecimento historiográfico. Na análise das fontes, como aponta Koselleck, o historiador se movimenta em dois planos: “analisa fatos que já foram antecipadamente articulados na linguagem ou então, com a ajuda de hipóteses e métodos, reconstrói fatos que ainda não chegaram a ser articulados, mas que ele revela a partir desses vestígios” (KOSELLEK, 2006: 305).

A memória é um desses rastros que o historiador pode transformar em fonte. Um resquício que persiste em continuar entre nós, que nos ajuda a estabelecer laços de identidade individual e coletiva. É por meio da recordação que muitas conexões de familiaridade são criadas no âmbito pessoal e coletivo. Catroga identifica três níveis de memória: a protomemória, a memória e a metamemória. A protomemória, de caráter passivo, diz respeito a nossa socialização e ao nosso habitus. Coloca a esfera de nossas ações no campo do automatismo. A memória propriamente dita se refere à recordação e ao reconhecimento. E a metamemória se relaciona com as representações que o indivíduo faz do que viveu. Esses dois últimos conceitos de caráter mais ativo - o sujeito e a coletividade buscam a anamnese. Essas categorias "também remetem para a maneira como cada um se filia ao seu próprio passado e como, explicitamente, constrói sua identidade e se distingue dos outros” (CATROGA, 2001: 15).

A memória se erige no embate entre os diversos campos mnésicos (coletivos e individuais) e na tensão tridimensional do tempo (passado, presente, futuro). Fazendo referência ao trabalho de Koselleck, Catroga acredita que o sujeito se recorda de acordo com 
suas necessidades presentistas, seu espaço de experiência e seu horizonte de expectativa. Assim, a memória é constituída a partir dessa numerosa rede relacional. Grande parte do que somos hoje interage não somente com memórias próprias, mas com uma série de outras memórias de outros indivíduos e sociedades. O ponto é tentar entender que memórias individuais e coletivas interagem para formar de uma identidade memorial, ${ }^{2}$ como aponta Tzvetan Todorov.

A recordação do passado é necessária para afirmar a própria identidade, tanto individual como de grupo. Um e outro também se definem, evidentemente, por sua vontade no presente e seus projetos de futuro; mas não podem prescindir dessa primeira lembrança (TODOROV, 2002: 199).

Essa construção não é resultado somente de uma recordação, mas também de um esquecimento: a memória "não é um armazém que, por acumulação, recolha todos os acontecimentos vividos pelo indivíduo" (CATROGA, 2001: 20). Como diz em nossa epígrafe, um homem sem recordação seria uma pedra inerte, um homem que somente se recorda também o seria. Temos o famoso exemplo do conto de Jorge Luís Borges, Funes, o memorioso, volta e meia evocado quando tratamos de assuntos relacionados ao tema memória. Após sofrer um acidente, Funes adquiriu a incrível capacidade de nada esquecer. Esse seu novo estado, contudo, trazia-lhe problemas. Funes passava o dia inteiro somente se recordando, deixando o conto a entender que não lhe sobrava tempo para mais nada. O conto termina de maneira abrupta, deixando-nos em dúvida se a congestão pulmonar que matou Funes teve alguma relação com seu estado de enfermidade memorial. A questão que fica para nós é que nossa identificação com o passado passa e deve passar pelo esquecimento para que haja possibilidade de vida.

Escolhemos muito do que queremos lembrar e muito do que queremos esquecer. A história de uma sociedade, por exemplo, constituí-se de lembrança e de amnésia. Por que devemos preservar uma memória em detrimento da outra? Voltamos ao jogo de subjetividades, escolhas e necessidades que existem por trás da construção da memória. As

\footnotetext{
${ }^{2}$ Para Paul Ricœur, a tensão entre memórias coletivas e individuais não é fácil de ser resolvida. Tentando discutir o que ele chama de "olhar interior" e "olhar exterior", o filósofo chega à conclusão de que: "nem a sociologia da memória coletiva nem a fenomenologia da memória individual conseguem derivar, da posição forte que ocupam respectivamente, a legitimidade aparente da tese adversa: coesão dos estados de consciência do eu individual, de um lado; capacidade das entidades coletivas de conservar e recordar as lembranças comuns, do outro". (RICOUER, 2010: 134).
} 
memórias não são somente recebidas, mas também são buscadas e selecionadas. Falar de uma simples imposição do passado seria negar o caráter criativo, subjetivo e imaginativo da memória e do esquecimento. As memórias são constantemente construídas e desconstruídas, renunciadas e ressuscitadas.

A recordação "pretende subordinar-se ao princípio da realidade, o que exige que as evocações, apesar de se conjugarem no tempo passado (anterioridade), mobilizem argumentos de veridição, tendo em vista garantir a fidelidade do narrado, mesmo que a sua única fiança seja o juramento do próprio evocador” (CATROGA, 2001: 22). Uma memória não é necessariamente fiel a uma realidade anterior, mas assim ela tenta se impor. A imposição de uma memória como verdadeira é baseado no caráter fiduciário do público. Porém, existem diferentes níveis de cobrança e autoridade para com a verdade de acordo com o lugar de fala do que evoca uma dada memória. Diante de um tribunal, o relato testemunhal é ouvido e submetido a diversos critérios de verificação. Ao evocar a memória, a testemunha sujeita-se a críticas diversas de prova e contra prova. No caso judicial, existem diferentes gradações de importância a serem atribuídos às diferentes evidências e testemunhas do caso analisado. Além do mais, a testemunha está também se submetendo a sanções judiciais que se baseiam em seu relato: sua fala pode trabalhar ao seu favor ou não, dependendo do transcorrer do processo e dos outros fatores envolvidos ao longo do certame. A verdade aqui adquire um elevado status de cobrança. Logo, nesse caso, um processo judicial tem como objetivo último esclarecer os fatos que se sucederam, estabelecendo uma verdade.

Assim também ocorre com a historiografia. Espera-se que o historiador escreva um relato verdadeiro sobre o passado ou, ao menos, que seu discurso seja baseado em critérios cientificamente aceitos de verificação e análise das fontes. Isso implica um elevado nível de cobrança da sociedade para com o historiador e dos historiadores para com outros historiadores. Não ter acesso direto ao passado, como bem lembra Carlo Ginzburg, não significa inacessibilidade à verdade. Mesmo que essa verdade possa ser variável de acordo com as perguntas, objetivos da pesquisa, interesses do presente, o dever último do historiador também é estabelecer uma verdade, uma verdade sobre o passado.

Um objetivo, no entanto, que nem sempre é alcançado. Assim como em qualquer outro ofício, o trabalho do historiador também está sujeito ao erro. O erro para os que estão profissionalmente envolvidos com a busca da verdade não é simplesmente um risco, mas uma “dimensão na qual se está constantemente imerso. O conhecimento humano não é apenas 
falível, mas progride através do erro. Tentando, errando, corrigindo-se. Erro e acerto (ou verdade) implicam um no outro, como a luz e a sombra” (GINZBURG, 2002: 102). Como é de se esperar, diferentes erros trazem diferentes consequências. Alguns erros podem trazer consequências mais graves, outros nem tanto. Em sua comparação entre juízes e historiadores, Carlo Ginzburg chega a uma conclusão que me parece correta, mas questionável em certo sentido. Ginzburg afirma que “em comparação aos os erros dos historiadores, no entanto, os erros dos juízes têm uma consequência mais séria e imediata. Eles podem levar à condenação de pessoas inocentes” (GINZBURG, 2002: 119). Claro, um erro judicial pode ter consequências mais imediatas: entre uma acusação e uma condenação, o tempo de espera, se comparado ao longo tempo que o historiador pode se propor a analisar, é curto. Dizer, entretanto, qual erro é mais grave - se o do juiz ou historiador - parece-me mais difícil de afirmar sem uma dúvida inquietante.

Os “erros” do historiador podem se ligar à maneira como utilizamos, enquanto sociedade, o passado, a memória e as funções que a história, enquanto disciplina, e a historiografia exercem. Memória e historiografia são categorias distintas, como argumenta Catroga:

não são lineares as relações entre a memória e a historiografia. Autores como Halbwachs distinguiram-nas: a memória histórica é um produto artificial, com uma linguagem prosaica e ensinável, destinado ao desempenho de papéis sociais úteis; ao contrário, a memória coletiva tem uma origem anônima e espontânea, uma transmissão predominantemente oral e repetitiva, e um cariz normativo. Também para autores como Febvre (1953), Marrou (1954) ou Nora (1984), a memória sacraliza as recordações, enquanto que o discurso historiográfico constitui uma operação intelectual crítica, que desmistifica e laiciza as interpretações, objetivando através de narrações que ordenam, sequencial $e$ sucessivamente, causa e efeitos, de modo a convencerem que a sua representação do passado é verdadeira (CATROGA, 2001: 39).

Se existem diferenças, também existem elementos convergentes, como a seleção, finalismo, o presentismo, as verossimilhanças e a representação. Também é forçoso ressaltar que a historiografia, apesar de não se confundir com a memória, produz memórias. Em todo o caso, a escrita da história é igualmente um trabalho de recordação que "também nasceu como um meio de combate contra o esquecimento, ou melhor, uma nova ars memoriae exigida pela decadência da transmissão oral e imposta pela crescente afirmação da racionalidade escrita” (CATROGA, 2001: 40). Nesse sentido, a historiografia exerce um importante papel social de formação das recordações e dos esquecimentos coletivos e individuais. 
Essa função da história de formar memórias coletivas pode ser melhor observada ao analisarmos como a escrita da história era tratada no século XIX. Um século marcado por uma historiografia que tem como uma das grandes propostas de produção a busca da gênese nacional, a formulação de uma concepção de identidade nacionalista e de uma memória nacional. É o século em que a história firmou-se como disciplina autônoma e como ciência (Cf. FURET, 1986: 109).

Temos como exemplo a criação e proliferação dos Institutos Históricos ao redor do globo e as funções que essas instituições se propunham a exercer. Notadamente influenciado por ideais iluministas, o Instituto Histórico e Geográfico Brasileiro (IHGB), fundado em 1838, surge como a primeira instituição que tenta pensar a história brasileira de forma sistemática, ancorada em noções historiográficas típicas da época, "tanto pelo tratamento linear dado ao desenvolvimento da história, quanto por sua instrumentalização como mestra da vida” (GUIMARÃES, 1988: 14). Essa concepção historiográfica trabalhada dentro do instituto produzia uma escrita que articulava passado, presente e futuro de maneira contínua, ancorada numa noção de progresso. Além do mais, preconizava uma história baseada nos grandes exemplos das civilizações pretéritas e nos heróis do passado nacional. Produção historiográfica e política de Estado formavam uma forte simbiose.

Para analisar essa formação das memórias individuais e coletivas e seus pretensos abusos, Ricœur trabalha com o que chama de “abusos da memória natural”. O autor aponta três níveis de abuso: nível patológico-terapêutico, nível prático e nível ético-político. Com relação no nível prático, o autor fala de uma memória instrumentalizada para analisar a manipulação tanto no âmbito individual, como no coletivo. As manipulações da memória “devem-se à intervenção de um fator inquietante e multiforme [como perguntas do tipo: quem sou eu?] que se intercala entre a reivindicação de identidade e as expressões públicas de memória” (RICOUER, 2010: 95). Trata-se aqui do fenômeno de legitimação de ideologias e poder, que se interligam com sistemas simbólicos imanentes à ação. É nesse campo ideológico que os abusos podem ocorrer por meio de narrativas "de fundação, narrativas de glória e de humilhação” que podem alimentar "o discurso de lisonja e medo” (RICOUER, 2010: 98). A coerção e legitimação da memória ocorrem no âmbito da narrativa, pois até o "tirano precisa de um retórico, de um sofista, para transformar em discurso sua empreitada de intimidação e sedução" (RICOUER, 2010: 95). Os discursos podem ser sempre redirecionados, selecionados, picotados, distorcidos de acordo com interesses dos que narram. Ou seja, ao mesmo tempo em que aparecem muitas memórias, outras tantas são esquecidas. É 
sob esse aspecto que podem surgir os manejos de uma história oficial, de uma história sacralizada e de uma memória celebrada, configurando-se o recurso narrativo em uma “armadilha” abusiva.

Esse tipo de história de que falávamos, baseado no estudo das grandes figuras, dos grandes heróis e na promoção do civismo, não ocupa mais um grande espaço nas produções historiográficas contemporâneas, mas a função social da disciplina (ou pelo menos uma delas), vista sob o ângulo do ensino, ainda nos revela que o:

ensino de História possui objetivos específicos, sendo um dos mais relevantes o que se relaciona à constituição da noção de identidade. Assim, é primordial que o ensino de História estabeleça relações entre identidades individuais, sociais e coletivas, entre as quais as que se constituem como nacionais (Parâmetros Curriculares Nacionais, 1997: 21).

Além do mais, os padrões curriculares nacionais falam em ensino de noções de cidadania e da importância do estudo da história para a “construção de noções de diferenças e de semelhanças. Nesse aspecto, é importante a compreensão do 'eu’ e a percepção do 'outro', do estranho, que se apresenta como alguém diferente” (Parâmetros Curriculares Nacionais, 1997: 22).

Como lembra Paul Ricœur, “uma memória exercida é, no plano institucional, uma memória ensinada; a memorização forçada encontra-se assim arrolada em benefício da rememoração das peripécias da história comum tidas como os acontecimentos fundadores da identidade comum” (RICOUER, 2010: 95). O historiador faz uma seleção do que considera importante ou não para o seu trabalho: define o tipo de fonte, define quais serão mais relevantes, define suas perguntas, faz um recorte temporal e espacial e escolhe ferramentas metodológicas e teóricas que utilizará ao longo de sua pesquisa. Em um sentido mais amplo, o historiador define assim quais memórias ele quer trabalhar e quais ele não quer trabalhar memórias que, se não trabalhadas, podem cair no esquecimento: o trabalho do historiador, assim como o trabalho da memória, também é um trabalho seletivo entre a amnésia e a anamnésia. Como aponta Carlo Ginzburg, “hoje acrescentaríamos que as ações humanas podem, contudo, influir poderosamente sobre a memória do passado, distorcendo seus vestígios, degredando-a ao esquecimento, condenando-a à destruição”(GINZBURG, 2001: 216). Então, o “erro” historiográfico pode constituir-se num verdadeiro abuso da memória, do esquecimento e do passado, pois é no exercício da memória e do esquecimento, como propõe Ricouer, que os abusos ocorrem. Servimo-nos dessa produção historiográfica e a partir dela fazemos nossas próprias construções de recordação, memória e esquecimento. Claro, 
historiadores estão constantemente imersos na dimensão do erro, porém, isso não retira as responsabilidades que seus erros podem acarretar. Deve-se ter responsabilidade sobre as memórias trabalhadas, elas podem ser reivindicadas por terceiros. Se o trabalho de um historiador também produz memórias e essa produção de memória ocorre num ambiente público, a ética do ofício carrega um forte peso de responsabilidade social.

Apesar dos historiadores estudarem as memórias dos vivos e dos mortos, o segundo campo mostra-se maior que o primeiro. Como apresenta Antoon De Baets, desde o surgimento da humanidade, a aproximação estatística de pessoas que já nasceram é de 106 bilhões. Dessas, 100 bilhões não estão mais vivas. Como argumenta o autor, os mortos não têm direitos, pois "na medida em que os mortos não são mais seres humanos, eles não constituem mais uma categoria dos que possuem direitos, porque, diferentemente das pessoas vivas, eles são incapazes de ter necessidades, interesses, deveres, fazer escolhas ou reivindicações, no presente ou no futuro” (DE BAETS, 2004: 135). Por mais óbvio que possa parecer, a responsabilidade para com os mortos parte daqueles que estão vivos. Esses são os que assegurarão a continuidade das memórias passadas no presente e no futuro.

Discutindo as implicações morais da distância espacial e temporal, Ginzburg chega à conclusão de que nossa "capacidade de contaminar e destruir o presente, o passado e o futuro é incomparavelmente maior que a nossa fraca imaginação moral” (GINZBURG, 2001: 216). Quando trabalhamos com memórias muito distantes temporalmente, todos os que vivenciaram diretamente aquela realidade não existem mais, sobrando apenas os vestígios memoriais daquelas pessoas. Não decorre disso uma ética, em teoria, mais frouxa para os que trabalham com essas memórias em comparação aos historiadores que trabalham com uma memória do tempo presente, pois “a consciência histórica de um povo frequentemente alcança eventos dolorosos velhos de muitos séculos” (DE BAETS, 2010: 116). Ginzburg teme, no entanto, que estender nossa “compaixão” (e acho que podemos falar também de ética) “a seres humanos muito distantes seria um ato de mera retórica” (GINZBURG, 2001: 218).

Todorov não fala exatamente sobre distância, mas acho que podemos nos reportar aos seus estudos para discutirmos um pouco mais sobre distância temporal, espacial e os usos do passado. Ao levantar uma discussão sobre vítimas que se transformam em perpetradores e sobre as contradições morais dessa condição, pressupõe certo sentimento de distância entre os acontecimentos. Cria-se a distância de identificação dos crimes cometidos aqui e lá. O afastamento é justificado de acordo com o interesse de cada sociedade: prisioneiros judeus 
torturados pelo exército alemão e prisioneiros palestinos torturados pelo exército israelense, nesse sentido, não poderiam ser comparáveis, pois seriam moralmente acontecimentos distintos e que serviriam a interesses distintos. Estabelece-se um discurso em que a tônica diz ser justo você torturar um palestino pela causa maior de Israel, mas um judeu, no contexto da Segunda Guerra, seria condenável. De fato, cada acontecimento tem que ser analisado em sua especificidade, mas Todorov aponta que ambos são moralmente abomináveis (TODOROV, 2002: 193-211).

Essa é uma discussão que também aparece no contexto de elaboração da Declaração Universal dos Direitos Humanos. Em busca de uma "visão geral da História”, De Baets analisa o preâmbulo de algumas versões e rascunhos da DUDH. Sobre algumas frases que aparecem relacionadas ao passado, “os abusos do passado são condenados em termos gerais” (DE BAETS, 2010: 88). Embora fizesse parte do contexto de elaboração da DUDH, as referências ao Holocausto e à história recente de guerras e arbitrariedades são - por vezes sim, por vezes não - suprimidas das versões posteriores com vistas a evitar uma restrição temporal. “Portanto, a DUDH enquadra suas referências ao passado tão acronicamente quanto possível” (DE BAETS, 2010: 88). Os abusos recentes são comparados aos abusos de outros períodos sob um mesmo estatuto ${ }^{3}$.

Se devemos manter o mesmo compromisso para trabalhar com a história do tempo presente e a história de um tempo mais remoto, há de se considerar que criamos relações diferentes com eventos delicados muito próximos de nossa realidade: "não se pode ignorar as condições históricas nos quais o dever de memória é requerido” (RICOUER, 2010: 99). É o caso aqui de fazermos menção aos regimes de exceção, aos grandes crimes contra a humanidade perpetrados ao longo do séc.XX e às reivindicações da sociedade por um direito à memória e à verdade de tais acontecimentos. Trabalhar com esses períodos pode ser problemático sob diversos aspectos.

Diferentemente de se trabalhar com uma história de um tempo mais remoto, as reivindicações memoriais podem partir ou de pessoas que vivenciaram diretamente a memória estudada ou de parentes e pessoas próximas. Surgem certos conflitos de interesse e de direito

\footnotetext{
${ }^{3}$ Deve-se atentar, no entanto, que essas comparações podem nos levar a incorrer em anacronismos. Discutindo o que chama de "direito ao silêncio”, De Baets formula algumas considerações sobre a questão do anacronismo. O historiador precisa saber que o uso de rótulos como "genocídio" e “crimes contra humanidade” podem alterar o estatuto legal e moral do acontecimento. É o caso, como exemplifica o autor, de definir os crimes perpetrados durante as Cruzadas de genocídio. Claro que utilizar termos que não existiam na época do acontecimento não significa dizer que as realidades que o termo tenta cobrir não existiram (DE BAETS, 2010: 94).
} 
que acabam por limitar os direitos dos historiadores de estudar determinadas memórias. É o caso do direito à privacidade do sujeito que o historiador estuda em choque com o direito de expressão do historiador. Ainda mais exemplar é o conflito entre o interesse do historiador de ter livre acesso a documentos e o interesse do Estado de resguardá-los por questões de segurança nacional ou qualquer outro motivo. Também não devemos esquecer o aniquilamento voluntário de documentos relacionados aos regimes ditatoriais, como aponta Todorov.

Os regimes totalitários do século $X X$ revelaram a existência de um perigo antes insuspeito: a supressão da memória. (...) As tiranias do século XX sistematizaram a apropriação da memória e aspiraram controlá-la de seus lugares mais escondidos. Essas tentativas fracassaram em algumas ocasiões, mas é verdade que, em outros casos (que por definição somos incapazes de listar), os vestígios do passado foram eliminados com êxito (TODOROV, 2002: 11).

Retomemos agora as reflexões de Paul Ricœur sobre os abusos da memória e do esquecimento para discutirmos sobre o dever de memória e o direito à memória no tempo presente. No terceiro nível, o nível ético-político, Ricœur fala de uma memória obrigada, de um dever de memória. De Baets argumenta que o direito à memória não implica um dever de lembrar-se, uma obrigação de recordar-se. Dever de lembrar-se entra em contradição com o direito de expressar opinião, que pode ser mantido em caráter público ou privado. O direito de expressar opinião pode ser ou não ser exercido. Se existe um direito à memória, existe também um direito ao esquecimento: um direito de não ser informado sobre o que aconteceu e o direito de não querer lembrar-se.

Dever de memória não deve ser confundindo com direito à memória. Todavia, no âmbito de uma falta pública, como argumenta Ricœur, o dever de memória aparece como o próprio imperativo da justiça: deve-se lembrar para que os crimes possam ser julgados, a verdade alcançada e as vítimas retratadas. Assim, o direito à memória transforma-se numa obrigação de lembrança para que as dívidas e feridas de uma sociedade sejam sanadas. O abuso pode ocorrer na medida em que os conceitos de justiça e reparação sejam desvirtuados, os crimes esquecidos ou os erros cometidos.

Trazendo a discussão para o contexto brasileiro, a criação de uma Comissão Nacional da Verdade, proposta a partir da terceira versão do Plano Nacional de Direitos Humanos (PNDH-3), tem a intenção de "examinar e esclarecer as graves violações de direitos humanos praticadas no período fixado no art. $8^{\circ}$ do Ato das Disposições Constitucionais Transitórias, a fim de efetivar o direito à memória e à verdade histórica e promover a reconciliação nacional” 
(Projeto de lei $n^{\circ}$ 7376/2010, 2010: 1). A comissão cobre um período que vai de 1946 até 1988 e tem como principais objetivos esclarecer as circunstâncias em que ocorreram os crimes de tortura, violações de direitos humanos, desaparecimentos e ocultação de cadáveres durante o regime militar brasileiro.

É uma comissão que interessa ao historiador por vários motivos. Aos historiadores brasileiros pode ter um duplo interesse: como cidadãos brasileiros, os historiadores também têm o direito de ter acesso à verdade sobre os acontecimentos que ocorreram durante o regime militar; aos historiadores que trabalham diretamente com esse período, a criação de uma comissão da verdade pode trazer novas informações para seus trabalhos de pesquisa, liberação de novas fontes e, por consequência, acesso a elementos antes desconhecidos; aos historiadores, independentemente de trabalharem ou não com o período, a comissão e o documento trazem categorias que envolvem diretamente seu ofício. São categorias tais quais direito à verdade, direito à memória, fatos.

O direito à verdade, como analisa De Baets, "é de importância cardinal para os historiadores, porque, em certo sentido, o que é chamado de 'direito à verdade', no direito internacional hoje em dia, nada mais é do que um componente crucial (embora não o único) do 'direito à verdade histórica' ou do 'direito à história”” (DE BAETS, 2010: 105). Como explicitado no próprio documento, a verdade que se busca com a Comissão da Verdade é justamente uma verdade histórica. Sob esse ponto de vista, a exigência ética que se espera da comissão é a mesma que se esperado historiador. Uma conclusão errada ou a falta de compromisso ético, crítico ou metodológico podem decorrer num abuso que, se não diz respeito a toda sociedade brasileira, afeta uma considerável parte.

Tanto o trabalho da Comissão da Verdade, quanto o trabalho do historiador podem ajudar no trabalho de luto e de memória de uma sociedade. Se existe uma ferida não curada na sociedade brasileira e pessoas reivindicam o direito à verdade, os fatos que se sucederam não foram devidamente trabalhados e esclarecidos e, portanto, o trabalho de luto não foi concluído. Somente com o esclarecimento desses crimes é que se pode iniciar um verdadeiro trabalho de memória e de luto. Trabalhar a memória não significa se utilizar dos acontecimentos passados com vistas a torná-lo um exemplo para as gerações futuras, mas sim ter conhecimento de que esses fatos abalaram de tal maneira nossas sociedades que não podem simplesmente ser relegados ao recalque sem serem devidamente discutidos em sociedade. 
Excesso de memória, como nos mostra o conto de Borges, e excesso de esquecimento podem ser ambos prejudiciais. A memória erigida entre a recordação e o esquecimento fundamenta quem somos, quais valores seguimos, ideais e princípios. Nossa própria identidade é ferida quando não existe a cicatrização de uma ferida e um trabalho social com nossas memórias.

O historiador tem, segundo Todorov, um compromisso com a verdade. Ele não pode ignorar documentos ou evidências que contradizem seu estudo. Também deve ter respeito e responsabilidade com as memórias que trabalha. Beatriz Sarlo faz uma advertência aos que trabalham com testemunhas dos períodos de regimes autoritários: considerar o testemunho como autoridade máxima daquilo que ele proclama como verdade seria incorrer num erro, "pois a sua retrospectiva não põe entre parêntesis as paixões, emoções ou afetos do sujeito evocador” (CATROGA, 2001: 39). Existe uma tensão entre aqueles que reivindicam a memória como testemunha do acontecimento e aqueles que se propõe a analisar esses discursos como especialistas. O imperativo de se lembrar é uma demanda da sociedade de querer saber o que aconteceu com seus familiares, seus amigos, com pessoas próximas. Lembrar liga-se ao direito à justiça e à reparação dos erros e crimes perpetrados.

Proclamar o estudo do passado como área de especialidade, o historiador pressupõe domínio dos conhecimentos da disciplina. Ao elaborar uma escrita sobre o passado, o historiador serve-se de uma série de ferramentas teóricas e metodológicas criteriosamente reconhecidas pela academia e com um forte viés científico. O historiador não possui o monopólio na elaboração do conhecimento sobre o passado, mas com certeza atribuí-se a ele um elevado status de autoridade. Essa autoridade, logo, deve ser administrada de maneira consciente, responsável e ética, pois o lugar último de uma historiografia é o público. Nunca se atua com memórias alheias de maneira completamente impune: o público, especializado ou não, pode querer resguardar, reivindicar ou criticar a maneira como as memórias são trabalhadas e apresentadas.

Se uma historiografia pode produzir memórias e esquecimentos e, por sua vez, memórias e esquecimentos podem construir identidades coletivas e individuais, deve-se ter muito cuidado e responsabilidade com o material que se produz e se distribui em público. Como foi dito, trabalhar com história do tempo presente ou de um tempo mais afastado não significa estabelecer relações éticas mais fracas aqui ou lá, pois o dever do historiador, independentemente do período que ele se propõe a analisar, é sempre com a verdade. Isso não 
significa dizer que a verdade, ou pretensa verdade, que o historiador busca, seja imutável, inquestionável ou inviolável, mas trabalhar entre o erro e o acerto não isenta os historiadores das consquências que seus trabalhos podem gerar. Existem, claro, estudos que afetam um número mais elevado de indivíduos, como no caso dos grandes crimes contra a humanidade, e estudos que afetam diretamente somente pessoas ligadas à área de estudo que o historiador trabalha. Porém, as memórias são dinâmicas e podem ser reivindicadas a qualquer momento.

BAETS, Antoon. "O impacto da Declaração Universal dos Direitos Humanos no estudo da História”, em História da Historiografia (Ouro Preto), 5 (setembro 2010), p.86-114.

"A Declaration of the Responsibilities of Present Generations toward Past Generations", em History and Theory 43 (2004), p. 130-164.

BILAC, Olavo. Defesa nacional: Discursos(a). Rio de janeiro: Bibliex, 1965.

Brasil. Congresso nacional. Projeto de lei n 7376/2010 que cria a Comissão Nacional da Verdade. Brasília, 2010.

Brasil. Secretaria de Educação Fundamental.Parâmetros curriculares nacionais : história, geografia/ Secretaria de Educação Fundamental. - Brasília :MEC/SEF, 1997.

CATROGA, Fernando. Memória, história e historiografia. Coimbra: Quarteto, 2001.

FURET, François. Oficina da história(a). Lisboa: Gradiva, 1989.

GINZBURG, Carlo. The Judge and the Historian: marginal notes on a late-twentieth-century miscarriage of justice. New York: Verso, 2002.

2001.

. Olhos de madeira: Nove reflexões sobre a distancia. São Paulo: Companhia das Letras,

GUIMARÃES, Manoel Luís Salgado. O Instituto Histórico e Geográfico Brasileiro e o Projeto de uma História Nacional. Em Estudos Históricos. Rio de Janeiro, n¹: 1988, p.5-27.

KOSELLECK, Reinhart. Futuro passado: contribuição à semântica dos tempos históricos. Rio de Janeiro: Contraponto, 2006.

RICOEUR, Paul. A memória, a história, o esquecimento. Campinas, SP: UNICAMP, 2010.

SARLO, Beatriz. Tempo pasado: cultura da memória e guinada subjetiva. São Paulo/Belo Horizonte: Companhia das Letras/ Editora UFMG, 2007.

TODOROV, Tezvetan. Memoria Del mal, tentación Del bien - Iindagación sobre El siglo XX. Barcelona: Ediciones Península, 2002. 